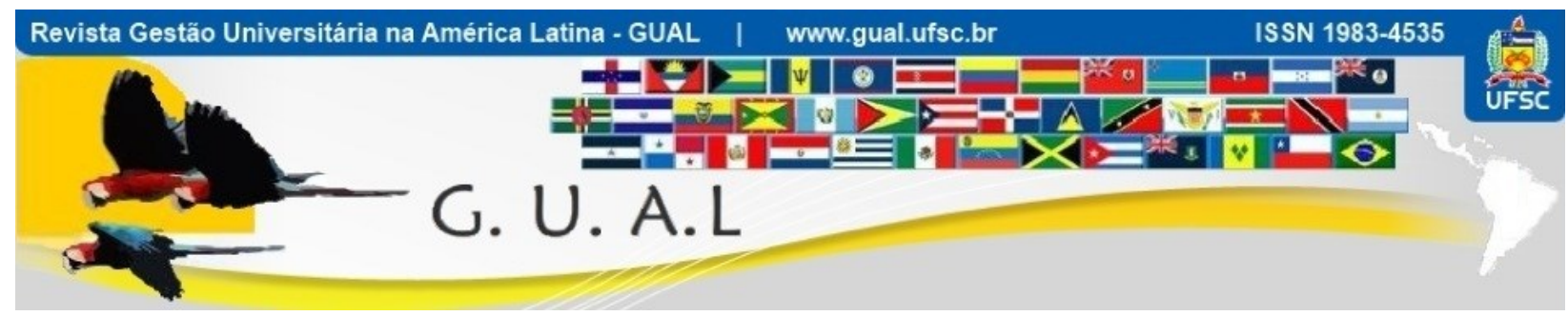

DOI: http://dx.doi.org/10.5007/1983-4535.2016v9n3p108

\title{
INCUBADORAS UNIVERSITÁRIAS DE ECONOMIA SOLIDÁRIA: METODOLOGIAS EM PERSPECTIVA
}

\section{UNIVERSITY INCUBATORS OF SOLIDARITY ECONOMY: METHODOLOGIES IN PERSPECTIVE}

Elisa Pereira Murad, Mestranda Universidade Federal de Itajubá - UNIFEI elisamurad@hotmail.com

Júlio César Andrade de Abreu, Doutor Universidade Federal Fluminense - UFF jandrade0@gmail.com

Recebido em 15/junho/2014

Aprovado em 23/maio/2016

Sistema de Avaliação: Double Blind Review

Esta obra está sob uma Licença Creative Commons Atribuição-Uso. 


\title{
RESUMO
}

Este trabalho aborda a temática de economia solidária e incubadoras desta natureza, as quais tem um papel importante por desenvolverem empreendimentos de economia solidária (EES) oferecendo assessoria, de modo que esses grupos possam se tornar autogestionários. $\mathrm{O}$ objetivo do presente artigo é analisar diferentes metodologias de incubação em universidades públicas, através dos eixos de acompanhamento, que são esses: legalização, viabilidade econômico-financeira, e capacitação e desenvolvimento humano. Foi realizado um estudo multicasos onde foram estudadas quatro incubadoras de EES, de diferentes localidades. São abordadas as características dessas incubadoras, detalhando suas metodologias, bem como as barreiras e desafios enfrentados no processo de incubação. Nota-se que enfrentam dificuldades independente do estágio de amadurecimento em que se encontram. Conclui-se que é importante aprimorarem ferramentas e metodologias de incubação, de modo que melhor atendam aos grupos incubados, através de um trabalho coletivo e solidário.

Palavras-chave: Economia solidária. Metodologias de incubação. Autogestão.

\begin{abstract}
This paper addresses the issue of solidarity economy and incubators of this kind, which plays an important role for developing solidarity economy enterprises (ESS) offering advice, so that these groups can become self-managed. The objective of this paper is to analyze different methods of incubation at public universities, through the axles of accompaniments, which are: legalization, economic viability, and human training and development. It was performed one multi-case study where four incubators EES, from different localities were analyzed. The characteristics of these incubators are discussed, detailing their methodologies, as well as the barriers and challenges faced in the incubation process. Was noted that they face difficulties independent of their maturation stage. It is concluded that it is important to hone tools and methodologies of incubation, so it can best treat incubated groups and to bring new solutions, through a collective and solidarity work.
\end{abstract}

Key words: Solidarity economy. Incubation methodologies. Self-management. 


\section{INTRODUÇÃO}

Diante de uma sociedade desigual, individualista e baseada no capital, surgem grupos que desenvolvem uma nova economia, baseada na cooperação, na solidariedade e no trabalho coletivo. Emergem-se novas relações de trabalho, que valorizam o ser humano e suas capacidades, atuando de forma autogestionária, e não submissa e exploratória. Essas novas experiências encontram-se na chamada Economia Solidária (ES), que em alguns casos, contam com o apoio e participação de universidades, poderes públicos, sociedade civil, entre outros.

Neste trabalho será abordada a temática da relação entre as universidades com a Economia Solidária. De modo mais específico, serão analisados os modelos e metodologias de incubação de empreendimentos de economia solidária (EES), que são vistos como nova forma de ampliar a relação universidade e comunidade.

Deste modo, as incubadoras atuam prestando assessorias aos EES, que em alguns casos, carecem de conhecimentos técnicos e recursos. Com oficinas e atividades oferecidas pela equipe da incubadora, busca-se organizar os participantes dos EES e instruir-lhes, de forma que criem uma dinâmica participativa, não havendo nesse processo sobreposição do saber formal ao saber comum. É interessante notar que as equipes responsáveis por difundir conhecimentos são de característica multidisciplinar, agregando assim diversos saberes no processo de incubação.

Esta pesquisa busca responder a seguinte questão: Como as diferentes metodologias de incubação de EES em universidades são aplicadas, a partir dos eixos de acompanhamento legalização, viabilidade econômica e capacitação?

Para responder ao problema da pesquisa este trabalho é composto de um estudo multicasos. O presente artigo está organizado em quatro partes, além desta introdução. Em um primeiro momento apresenta-se o embasamento teórico sobre Economia Solidária e Incubadoras de Empreendimentos Solidários. Em um segundo momento é detalhada a metodologia desta pesquisa. Após isso, são apresentados os casos estudados que compreendem quatro diferentes incubadoras, de diferentes estágios de amadurecimento, as quais serão representadas pelas letras $\mathrm{A}, \mathrm{B}, \mathrm{C}$ e D, procurando assim preservar a identificação dos projetos, das universidades e dos entrevistados. Em seguida são detalhados os resultados e, finalmente, são tecidas as considerações finais. 
O objetivo do artigo é analisar diferentes metodologias de incubação em universidades públicas, através dos eixos de acompanhamento, os quais são de suma importância serem desenvolvidos junto aos cooperados, através das assessorias. Abordam-se também as características gerais das incubadoras e os desafios enfrentados pelas mesmas.

O estudo torna-se relevante por tratar o impacto da implantação de uma incubadora deste segmento e sua metodologia utilizada, os quais se tornam importantes tanto para a comunidade onde está inserida como também para a universidade, se mostrando como uma grande experiência para os alunos e trazendo bons resultados ao assessorar empreendimentos solidários.

\section{REFERENCIAL TEÓRICO}

\subsection{ECONOMIA SOLIDÁRIA}

O conceito de economia solidária nasceu na França, através dos trabalhos de Jean Louis Laville e Bernard Eme, e se referia às iniciativas cidadãs e novas formas de solidariedade, visando o bem comum e desenvolvimento social (FRANÇA FILHO, 2003). Veio como alternativa diante do sistema econômico vigente onde há crescente índice de desemprego, exclusão social e desigualdade de renda. Estas iniciativas são caracterizadas desde as autônomas às que possuem apoio do poder público, e conforme dissertado por Paes e Calbino (2013) podem estar organizadas em formas coletivas e também individuais (este último defendido por alguns autores).

De acordo com França Filho e Laville (2004) as formas assumidas por esta economia variam de cooperativas de produção e prestação de serviços, passando por bancos comunitários, clubes de troca e associações de serviços em países latino-americanos, até as cooperativas sociais, as sociedades cooperativas de interesse público, as empresas sociais ou os sistemas de trocas locais, entre outros, em países europeus. Conforme Coraggio (2003), autor que defende a importância de se desenvolver uma nova consciência de estrutura econômica, estas formas gerenciam os recursos e necessidades de seus membros e da comunidade, que trabalham para o social e não para o capital.

Em meio a uma realidade onde se encontra a hegemonia de um modelo político e econômico explorador, excludente e individualista, surge um novo modelo, que de acordo com Cunha (2003), é um modelo de resistência ao capitalismo. Neste novo modelo impera a cooperação, transparência, democracia e autogestão, onde os integrantes são detentos dos seus 
próprios meios de produção e saber. Há equidade entre direitos e responsabilidades e não há a constante competitividade e procura incessante pelo lucro.

Em se tratando desta procura pelo lucro, nota-se a grande força que é exercida pelo capitalismo e os processos que ele procura ocultar devido ao fato deste sistema ser voltado à produtividade, riqueza e à capacidade de fazer ruir as estruturas de amparo da sociedade, impondo ao coletivo o interesse daqueles que trabalham para o desenvolvimento capitalista. Os processos ocultados são: a) quanto a outras possibilidades de organização da sociedade, que procuram gerar bem-estar; b) quanto à existência de outros princípios de organização nãomercantil; c) quanto ao surgimento e virtudes de outras organizações econômicas (LAVILLE, 2005 apud GAIGER, 2008). Conforme Gaiger (2008) este modelo cria uma racionalidade intrínseca que se conflita com os princípios da organização social, subjugando-os.

Tendo em vista esta força individualista e ocultadora, torna-se necessário reforçar o conceito de solidariedade, que para Souza (2003, p.34) "é um fundamento ético que orienta a formação de redes e implica em responsabilidade social e conciliação de interesses comunitários por meio da participação de atores e de organizações sociais", focando no individuo e no interesse coletivo. Assim, há o nascimento de iniciativas sociais em diversos países, que conforme exposto por França Filho (2003), são portadoras de um caráter novo, relativo ao seu novo modo de funcionamento e sua finalidade. Essas experiências reúnem usuários, profissionais e voluntários, preocupados com a geração de trabalho e renda, e interessados em reforçar a coesão social e os laços entre os indivíduos.

Neste novo cenário, os trabalhadores possuem posse coletiva dos seus meios de trabalho, havendo respeito mútuo entre todos. Quanto se fala em autogestão, trata-se dos próprios membros gerirem seu empreendimento, onde há participação de todos e suas responsabilidades são bem distribuídas, oferecendo direitos iguais a voto sem concentrar o poder de decisão na mão de poucos. É a aplicação da democracia no processo de gestão (SINGER, 2008).

A economia solidária está se constituindo em uma rede mundial e os envolvidos estão engajados na luta pela liberdade e mudança do contexto social, enxergando uma diferente forma de desenvolvimento. O foco é voltado para o consumo responsável e no respeito ao meio ambiente e às pessoas, havendo igualdade e senso de justiça entre os membros (SINGER, 2003). Além da troca de bens e serviços, neste modelo ocorre a troca de ideias e a integração entre os membros, havendo a efervescência cultural, promoções de festas entre outros eventos, com um olhar para além do lazer, mas também político, e para muitos até as 
atividades de Economia Solidária acabam se tornando um hobbie. Existe outro papel além de apenas satisfação econômica. É o combate da exclusão social através de uma organização social, política e cultural, a procura de acesso aos direitos cidadãos.

Quanto a essa acessibilidade aos direitos, tem-se no modelo de desenvolvimento hegemônico grande polarização do poder, o qual se concentra nas mãos dos capitalistas, que destituem a maioria dos poderes de decisão. A massa trabalhadora torna-se alienada, não participando dos processos decisórios e não tendo o domínio do processo por inteiro, sendo meras peças para o alcance do objetivo maior da empresa que é gerar lucro. Mas este é um modelo que está aos poucos entrando em crise. Ocorrem casos de ao a empresa falir, trabalhadores se apropriarem deste empreendimento em forma de cooperativa começando a desenvolver a autogestão, numa forma democrática, participativa e justa. Deste modo, essas pessoas ao viverem essa nova experiência, independente das barreiras enfrentadas, não voltarão ao trabalho de antes, pois compreendem que esta é uma experiência libertadora (SINGER, 2008).

Singer (2008) complementa que neste contexto a economia solidária toma um papel de desenvolver o individuo, de ensinar, formar, crescer e amadurecer, oferecendo um ambiente de trabalho melhor e igualitário, sem concentração de poder, podendo o individuo realizar diversas tarefas e dominar diversos saberes. O trabalho é visto como aprendizado e crescimento, e não como dominador e explorador. Arruda (2000) diz que a produção deve ser encarada como um meio e não como fim, de forma que esteja a serviço do desenvolvimento do ser humano de forma integral, sanando necessidades muito além do que as materiais; o autor também comenta que as pessoas devem procurar sair do paradigma dominante de ver o mundo. Esse é o verdadeiro desenvolvimento, um desenvolvimento como liberdade.

Como definido por Sen (2000, p.25):

as liberdades não são apenas os fins primordiais do desenvolvimento, mas também os meios principais. Além de reconhecer, fundamentalmente, a importância avaliatória da liberdade, precisamos entender a notável relação empírica que vincula umas às outras, liberdades diferentes. Liberdades políticas (na forma de liberdade de expressão e eleições livres) ajudam a promover a segurança econômica. Oportunidades sociais (na forma de serviços de educação e saúde) facilitam a participação econômica. Facilidades econômicas (na forma de oportunidades de participação no comércio e na produção) podem ajudar a gerar a abundância individual, além de recursos públicos para os serviços sociais. Liberdades de diferentes tipos podem fortalecer umas às outras.

Mas ao se tratar dessa nova forma de economia, encontramos barreiras inicialmente devido à escassez de capital e tecnologia, insuficiente acesso ao mercado e a informações, 
bem como também dificuldades quanto à legalização de cooperativas (SINGER, 2008). Muitos não possuem conhecimentos técnicos, outros ainda não possuem alfabetização completa e necessitam de assessoria financeira, tecnológica, fiscal e legal. Neste contexto vemos a importância dos movimentos de economia solidária por meio de Fóruns Sociais, atuação de universidades e incubadoras que procuram aumentar a integração entre os projetos e as redes, melhorar o canal de comunicação, e auxiliá-los para que se tornem autogestionáveis e possam seguir adiante com êxito.

\subsection{INCUBADORAS DE EMPREENDIMENTOS DE ECONOMIA SOLIDÁRIA}

Diante da crescente luta pela economia solidária, as universidades apresentam um importante papel, através de sua riqueza de conhecimento, ideias inovadoras e necessidade de atuação junto às comunidades visando o desenvolvimento social, político, econômico e cultural das mesmas. Neste contexto as incubadoras são essenciais e estão cada vez mais ganhando apoio e abrangência no nosso país, juntamente com a crescente força de fóruns, seminários e congressos que vêm ano a ano construindo redes e oferecendo apoio às iniciativas de economia solidária. As incubadoras atendem as demandas tanto dos trabalhadores como também as dos poderes públicos que procuram parcerias para apoiar a formação dessas iniciativas.

De acordo com Singer (2003) as incubadoras colocam os recursos humanos e científicos das universidades a serviço da luta contra a exclusão e pobreza, desenvolvendo e capacitando, a procura de obter resultados significativos. Para Gattai e Bernardes (2013) elas tomam um papel prático e reflexivo, fazendo que os envolvidos nesse processo de desenvolvimento criem diálogos e se integrem de forma a refletir e buscar soluções aos problemas coletivamente; cria-se autonomia do ponto de vista econômico, social, político e cultural. Este diálogo ajuda a aumentar o sentimento de pertencimento ao grupo e melhora de autoestima, potencializando as ações de cada membro (SAWAIA, 2001 apud GATTAI e BERNARDES, 2013).

Nessas incubadoras há a articulação multidisciplinar das áreas do conhecimento, havendo a participação de alunos de vários cursos praticando o que aprendem em sala de aula, fazendo o acompanhando das iniciativas incubadas, oferecendo assessoria e formando-as, por intermédio de metodologias de gestão (CANÇADO et al, 2011).

A metodologia desenvolvida por Cançado e Cançado (2009) se baseia no uso de indicadores de desempenho, sendo este um método participativo e dialógico entre os 
participantes, trabalhando os seguintes eixos: Legalização, Viabilidade Econômico-Financeira e Capacitação/Desenvolvimento Humano. Esses eixos se dividem em Indicadores, e os Indicadores em Variáveis.

O uso de indicadores, conforme Wautiez et al (2003) auxilia na avaliação da estabilidade do empreendimento, do grau de coesão e confiança, indicando situações, mostrando limites, e aumentando oportunidades de acompanhamento das ações humanas.

Além dos eixos citados acima, também são realizados projetos quanto à educação, saúde, meio ambiente e cultura. Acredita-se na indissociabilidade do Ensino, Pesquisa e Extensão, que em prática se manifestam pelos grupos de debates, pesquisas de campo, projetos desenvolvidos com os associados etc.

Quanto aos indicadores, é importante salientar que sua construção requer reflexão sobre o que, como e para quem estamos analisando os dados. Começa com as escolhas das variáveis que se pretende monitorar e qual perspectiva será privilegiada. Uma característica diferenciada da economia solidária é que o desenvolvimento desses indicadores ocorre através de um debate democrático para definição dos mesmos (WAUTIEZ, 2003). Em um processo de avaliação de empreendimentos solidários, é crucial a escolha dos indicadores de modo a contemplar o interesse de todos os sujeitos envolvidos (CRUZ, 2005).

A proposta de metodologia baseada na obra de Cançado (2009), a qual foi descrita nesse trabalho, está orientada pelas seguintes premissas: a) não diminuir a autonomia do grupo; b) velocidade de incubação, afinal cada iniciativa tem sua própria característica, e assim, um tempo de desenvolver e se tornar autossustentável; c) veracidade dos diagnósticos realizados, não podendo haver a manipulação de resultados; d) dar feedback e com isso planejar ações futuras (CANÇADO et al, 2011).

Os que participam desse processo de incubação, os técnicos e acadêmicos, têm um importante trabalho e necessitam de muito cuidado ao aplicar os conhecimentos. Além das premissas citadas no parágrafo anterior, existe uma forma especial de lidar com os cooperados, pois são culturas e educações distintas e é necessária uma forma de explicar e aplicar os conhecimentos, utilizando uma linguagem de fácil entendimento e respeito ao tempo de aprendizado de cada um. Uma das características dessas práticas é o respeito às pessoas, portanto não pode haver sobreposição do saber formal (acadêmico) ao saber popular. Assim, deve-se promover a autonomia dos associados, mantendo-os sempre ativos e deste modo eles se sentirão motivados a desenvolverem suas habilidades e senso crítico (CANÇADO et al, 2011). 
Os alunos também tem uma grande participação junto com os incubados e acabam se desenvolvendo nesse processo, ao realizar oficinas, trocar ideias e experiências, gerar debates e eventos acerca do tema, além de organizar os resultados obtidos pelas cooperativas. Sendo assim, de acordo com Cançado et al (2011) os indivíduos passam a entender e acompanhar as alterações nos valores dos indicadores, procurando sanar suas deficiências. $\mathrm{O}$ andamento de todo o processo deverá ser acompanhado por uma metodologia que acompanha os resultados de cada etapa, desde a criação do estatuto e regularização à capacitação completa dos associados.

O processo de inucubação geralmente se inicia por meio de reuniões periódicas, levantamento de dados, avaliação da documentação, realização de diagnósticos, viabilização de ações nos eixos educação, saúde, meio ambiente e cultura, sendo necessário conhecer o perfil e as necessidades da cooperativa e dos envolvidos, e assim criar instrumentos de acompanhamento e auxílio (CUNHA et al, 2011).

É importante salientar que as incubadoras também enfrentam nesse processo muitos desafios, tanto econômico como pedagógico e sócio-político (CRUZ, 2004). É tratado um processo complexo que envolve relações interpessoais, bem como pessoas com diferentes envolvimentos no tema, e em frente a isso se encontra como barreiras a falta de participação discente, editais públicos limitadores e dificuldade em se realizar oficinas e cursos com a comunidade (GHIZONI e CANÇADO, 2013). Encontra-se também a falta de apoio do poder público, de recursos, de engajamento de alguns cooperados, poucas parcerias, o desejo imediatista dos membros em se obter resultados econômicos etc.

Deve-se enxergar que as cooperativas acabam se tornando mais que um simples grupo produtivo, ela se torna um centro de articulação e discussão do desenvolvimento local, enxergando a comunidade como um todo. Logo, a atuação das incubadoras torna-se de suma importância para o desenvolvimento desses grupos.

\section{METODOLOGIA}

Este trabalho é um estudo de casos múltiplos ou estudo multicasos, onde foram estudadas quatro incubadoras de cooperativas populares da região sudeste do país, duas do estado de Minas Gerais e duas do estado do Rio de Janeiro. Para a construção desse artigo foi realizado, em um primeiro momento, uma pesquisa bibliográfica sobre os temas de Economia Solidária e Incubadoras de Empreendimentos de Economia Solidária. Sobre pesquisa bibliográfica, Gil (2008) afirma que é uma pesquisa desenvolvida a partir de um material já 
elaborado, constituído principalmente de livros e artigos científicos. Uma grande vantagem oferecida é que permite ao investigador a cobertura de uma gama de fenômenos muito mais ampla.

Tendo em vista os objetivos do trabalho, foi realizada uma pesquisa de caráter descritivo, que de acordo com Gil (2008, p.28) uma pesquisa desse tipo "tem como objetivo primordial descrições das características de determinada população ou fenômeno ou estabelecimento de relações entre variáveis". Assim, buscou-se conhecer as diferentes metodologias de gestão aplicadas nas incubadoras, procurando entender o modo de atuação junto às iniciativas incubadas, dando uma maior ênfase ao desenvolvimento da Economia Solidária no nosso país.

Os dados foram obtidos através de entrevistas por videoconferência, presencialmente, e de uma pesquisa de campo, através de uma visita técnica a uma das incubadoras. Vale ressaltar a dificuldade em conseguir agendar as entrevistas, devido à distância geográfica e disponibilidade de horários dos coordenadores das incubadoras. As entrevistas seguiram um roteiro pré-estabelecido, porém dando margem a comentários e questionamentos adicionais, se caracterizando assim por uma entrevista semi-estruturada.

As questões abordadas na pesquisa se referem à criação das incubadoras estudadas, às características dos empreendimentos incubados, às barreiras e desafios enfrentados, às metodologias aplicadas, e o uso de indicadores de desempenho e seus eixos (conforme metodologia definida por Cançado et al, 2011).

As identificações das incubadoras e dos entrevistados foram preservadas, e no trabalho as incubadoras foram codificadas em A, B, C e D. Quanto à codificação, a A seria uma incubadora de estágio de amadurecimento avançado, que conta com dezenove anos de existência; a B, a qual foi criada em 2009, está em estágio intermediário de desenvolvimento e possui uma metodologia de incubação consolidada; a $\mathrm{C}$, que possui pouco mais de cinco anos de existência, é também de estágio intermediário, e passou no ano de 2013 por momentos de turbulência, mas já está se reestruturando; a D está iniciando o seu desenvolvimento no momento, tendo seu projeto sido aprovado no ano de 2013 por edital público.

\section{RESULTADOS E DISCUSSÃO}

A Economia Solidária vem como uma alternativa de trabalho, renda e cidadania e está em desenvolvimento no país, contando atualmente com um crescente apoio e engajamento das universidades, que procuram estreitar os laços com a comunidade através de seus projetos de 
extensão. Destes projetos, têm-se diversos casos que fizeram nascer incubadoras de economia solidária (comumente conhecidas por incubadoras tecnológicas de cooperativas populares ITCP). Neste meio encontramos envolvimento de professores, alunos, técnicos, cooperados, poderes públicos, sociedade civil e empresas, muitos desses na perspectiva de desenvolvimento de uma nova forma de se fazer economia, através da solidariedade e cooperação.

Por meio do trabalho realizado pelas incubadoras, esperam-se formar cooperativas de alto solidarismo, sendo visto por Gaiger (2007) àquelas que atendem aos pontos de coletividade, gestão transparente e participativa, matérias-primas ou insumos de origem solidária, comercialização solidária a qual conta com a preocupação com os consumidores, participação em movimentos sociais e em redes, e ações de preservação do ambiente natural.

Para o presente caso foram analisadas quatro incubadoras de diferentes municípios com características próprias, todas nascidas de universidades públicas e que possuem o mesmo objetivo, o de oferecer assessoria para que esses empreendimentos se tornem autossustentáveis, viáveis economicamente, organizados e legalizados, capacitados, e que prezem pelo desenvolvimento das competências dos indivíduos. A participação dos técnicos e alunos nesse processo torna-se fundamental, pelo fato de realizarem a sensibilização dessas iniciativas e estarem no papel de facilitadores, fomentando o pensamento crítico de cada membro do grupo.

A incubadora A encontra-se em estágio avançado, localizada em uma cidade capital, tendo seu projeto nascido no ciclo de ações de combate à pobreza em 1995, em um centro de alta tecnologia, difundindo-se num sistema complexo de parcerias (BOCAYUVA, 2001). A incubadora conta com uma universidade que fornece uma série de recursos, estando ligada ao trabalho de extensão da faculdade, possuindo em sua equipe vários bolsistas desses projetos e, além disso, também possui outros bolsistas ligados ao CNPq (Conselho Nacional de Desenvolvimento Científico e Tecnológico), e vale ressaltar que contam também com técnicos de incubação, construindo assim uma equipe multidisciplinar e ativa. Trabalham hoje com aproximadamente quarenta empreendimentos, sendo que dezessete cooperativas fazem por volta de quinze anos que estão em incubação, mostrando assim a complexidade de incubar iniciativas de economia solidária, pois para isso não há um tempo determinado, cada grupo caminha de uma maneira, e é necessário respeitar o tempo de desenvolvimento de cada um. 
As incubadoras $\mathrm{B}$ e $\mathrm{C}$ se encontram em um estágio intermediário, ou seja, existem há poucos anos e tem ainda o que desenvolver quanto a alguns tópicos, como gestão, metodologia, recursos e parcerias.

Quanto à $\mathrm{B}$, se trata de uma incubadora de uma cidade de médio porte e foi criada em 2009, em um campus novo, como projeto de extensão. A incubadora mostrou ter uma boa participação nos editais. Conta com uma equipe de sete alunos, sendo que uma recémformada conseguiu ser contratada como assistente técnica pelo PRONINC. Quanto aos empreendimentos, hoje incubam três grupos, sendo que não ocorreu ainda desincubação. Um grupo é uma associação de produtores que trabalham com uma fruta típica da região e muito utilizada na culinária. Outro grupo é uma cooperativa formada por beneficiárias do Bolsa Família, as quais produzem doces, marmitas, quentinhas e salgados. O terceiro grupo é uma cooperativa de horticultura.

Já a cooperativa $\mathrm{C}$, também localizada em uma cidade de médio porte, teve seu início há pouco mais de cinco anos e atualmente conta com uma equipe jovem. Chegou-se a ter dois técnicos (assessores), uma técnica servidora pública deslocada pra trabalhar na incubadora, tinha uma figura de um coordenador, e alguns professores envolvidos pelos projetos; o próreitor participava um pouco também. A equipe acabou se reduzindo bastante, com a saída da técnica e dois assessores técnicos. Também havia um convênio com a prefeitura, a qual viabilizava o pagamento dos técnicos. Esse convênio se encerrou no ano de 2013 e depois foi renovado, em um processo mais longo e só agora está sendo assinado, por isso que no momento estão sem assessores. A incubadora já teve seis iniciativas incubadas; atualmente estão com três empreendimentos: um ligado ao artesanato, outro de produtores rurais, e o terceiro é uma associação de catadores de materiais recicláveis.

A última incubadora analisada, codificada em D, é uma incubadora que está em seu estágio inicial, tendo sido aprovada no final de 2013, trabalho este que foi resultado de um longo período de atuação na região, através de contato com diversos grupos e debates acerca de economia solidária. A trajetória iniciou desde 2006, procurando dar assessoria a certos grupos, porém devido à alta rotatividade dos mesmos, eles acabaram se desmobilizando e não se consolidaram. A partir desses fatos, resolveu-se fazer outra abordagem, de começar um trabalho de economia solidária na região. A ideia inicial foi criar um Fórum Regional de economia solidária. Começaram a fazer reuniões, mas contavam com pouca participação dos envolvidos. No final de 2012, surgiu a ideia de organizar uma espécie de seminário, mobilizando pessoas a discutirem e começarem a se reconhecer, para depois organizar um 
Fórum. Estes seminários passaram a ocorrer em 2013, e em um deles foi-se comentado do edital do CNPq para incubadoras, e assim o grupo submeteu uma proposta e a mesma foi aprovada.

A equipe da incubadora acima conta com a participação de quinze pessoas, entre eles professores, alunos, técnicos, e educadores populares. É uma equipe que está em processo de formação, e que irá começar a incubar quatro empreendimentos. O primeiro é uma cooperativa de catadores de materiais recicláveis, o outro é um grupo de artesãs, o terceiro é um grupo de beneficiárias do programa do governo Bolsa Família, e o quarto é um projeto de Restaurante-Escola, que possui como papel uma atuação semelhante à de uma incubadora.

Nota-se que são incubadoras de diferentes localidades e características, cada uma nascendo de determinado contexto e passando por situações distintas. Serão relacionadas abaixo características quanto às barreiras enfrentadas, metodologia desenvolvida, e análise dos eixos de Legalização, Viabilidade Econômica e Capacitação, eixos esses estudados pela metodologia de indicadores de Cançado (2009).

\subsection{QUANTO ÀS BARREIRAS E DESAFIOS}

Muitas são as barreiras e desafios enfrentados por essas incubadoras, e é importante salientar que independe do estágio de amadurecimento de tal, pode ser tanto no seu início, no começo de seu desenvolvimento, quanto no nível de alto desenvolvimento, em que se possui uma metodologia sólida e equipe bem formada.

No caso da incubadora A, a mais antiga do caso, passa por desafios quanto a formar grupos diante da mentalidade de imediatismo desses, onde eles têm necessidade de sobrevivência e não conseguem enxergar benefícios no momento de capacitação; eles desejam ferramentas e não o conhecimento, então o papel da incubadora se faz na sensibilização desses grupos sobre os benefícios que irão conquistar e no trabalho anterior a isso.

Para a incubadora $\mathrm{B}$, a primeira barreira enfrentada foi a estrutural, pois de início não tinham espaço de funcionamento e nem mesmo recursos, como por exemplo, computadores para os alunos trabalharem; a segunda barreira é a relação de número de professores envolvidos com o tema, que é um número muito baixo; há a falta de participação de alguns membros de iniciativa incubada; existe o desafio quanto aos valores e culturas dos grupos, e de fazer com que os mesmos enxerguem uma nova perspectiva; dificuldade em se conseguir acesso ao cadastro das beneficiárias do programa Bolsa Família; resistência de articulação do 
poder público, devido às mudanças de interesses e de gestão; prefeitura não dá auxílio, nem subsidiando técnicos nem oferecendo transporte; falta de pró-atividade dos alunos.

Quanto a C, julga-se que a permanência de uma incubadora em uma universidade não é tão tranquila, porque nem sempre se recebe apoio, e ocorre do trabalho desenvolvido ser incompreendido por alguns. A incubadora quase chegou a fechar as portas em 2013, mas conseguiram se reestruturar. Têm-se como barreiras os recursos, o entendimento de alguns professores da importância do papel de uma incubadora de tecnologia social na universidade, e por último o envolvimento dos discentes, pois não é do perfil dos alunos da universidade se envolverem em projetos dessa natureza.

A incubadora D também tem enfrentado alguns desafios, os quais são muito naturais em sua situação por estar em estágio inicial. Fazem-se críticas ao edital pelo tempo de duração (apenas dois anos) e o limite de recurso, que é pouco, sendo que exige que a incubadora comece trabalhando com no mínimo quatro empreendimentos, ou seja, dificultam o trabalho por começar com uma demanda grande em vista aos poucos recursos recebidos e ferramentas desenvolvidas.

\subsection{METODOLOGIAS DE INCUBAÇÃO}

\subsubsection{Incubadora A}

A incubadora encontra-se atualmente desenvolvendo um projeto de certificação, onde está sendo criada, juntamente com as cooperativas, uma metodologia de incubação, com foco nos processos. Contam também com um projeto do CNPq de revisão de metodologia, com um foco mais aplicativo, pois além de construir algo, tem também que viabilizar. Serão levados em conta os elementos de cada etapa definida, facilitando assim posterior medição.

A metodologia de incubação utilizada se baseia em cinco fases: Na fase 0 é quando difunde-se a proposta da incubadora, seleciona-se os grupos e realiza-se a sensibilização. É uma fase crucial para a continuidade do processo, pois é quando acolhe o grupo, fazendo com que eles percebam que aquele é um espaço de discussão e de compreensão de todas suas necessidades. Após isso eles passam para o trabalho de formação, e para cada aula tem-se um técnico específico. $\mathrm{Na}$ fase 1 , é quando os grupos constroem seus projetos, assim como também devem se formalizar e demonstrar os princípios cooperativistas na prática. Na fase seguinte, a 2, o grupo deve executar, avaliar, e se necessário corrigir o projeto, respeitando o que foi definido pelo grupo. Na terceira fase é quando se espera que o grupo expanda seus 
princípios cooperativistas e suas ações econômicas a um entorno social de maior escala, visando demonstrar uma maior autonomia e iniciativa. Na última fase, a quarta, é quando se aplica o conhecimento adquirido, corrigindo dificuldades e desenvolvendo ferramentas; também se analisa a capacidade do grupo de "andar com suas próprias pernas" (Disponível no site da incubadora, no tópico "Os tempos de incubação"). Mas mesmo que o grupo não esteja mais em incubação, a incubadora permanece de "portas abertas", pois tudo isso não é visto como um processo findo.

O processo descrito de incubação poderá ser visualizado na figura abaixo:

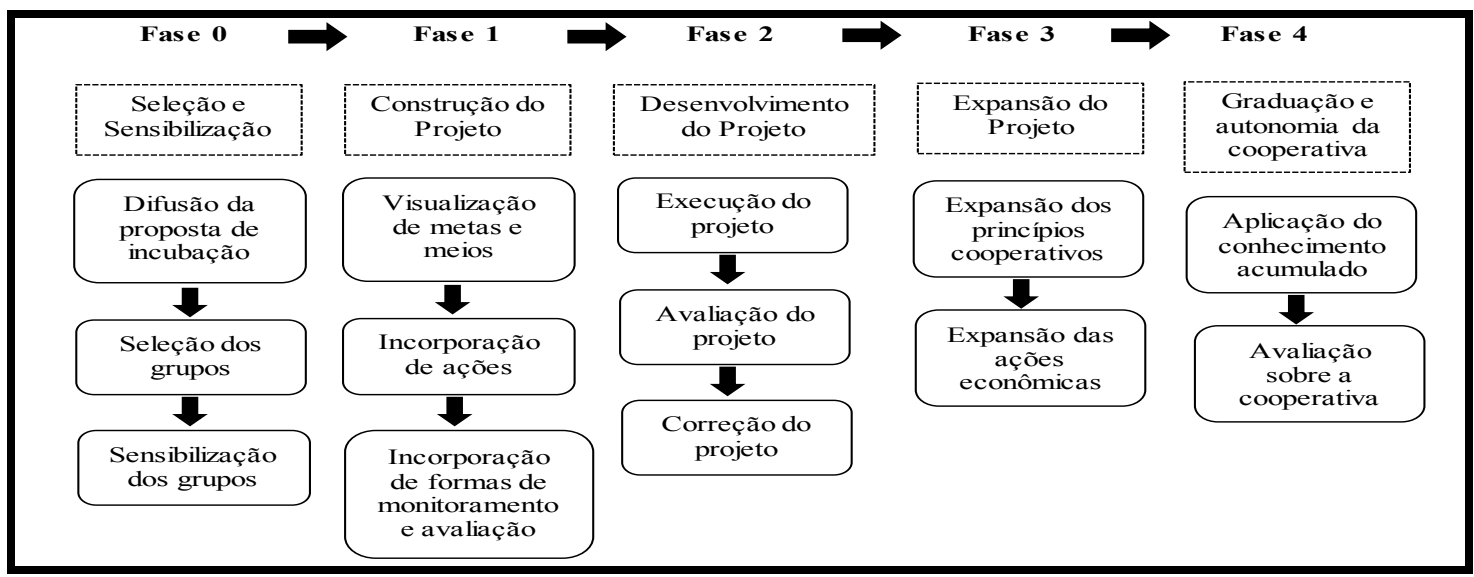

Figura 1 Tempos do Processo de Incubação.

Fonte: Elaborado pelas autoras, com base na pesquisa.

\subsubsection{Incubadora B}

A metodologia utilizada por esta incubadora é baseada em uma já existente, onde tem o processo dividido em três partes. Primeiro se faz um contato inicial, onde ocorre a apresentação da incubadora e de como a mesma trabalha, conhecendo assim o grupo. Depois se passa para o processo de formação específica, em que se conhecem as demandas do grupo e assim elabora-se o que fazer no processo de incubação. Por último tem a ação "mantenedoura". Nesta última fase ocorre a inauguração do empreendimento, e a partir daí não haverá mais um acompanhamento tão sistemático semanal e quinzenal, como era feito para acompanhar as iniciativas em incubação.

As reuniões com os grupos ocorrem geralmente quinzenalmente (no mínimo). Discutem-se vários tópicos, como por exemplo, ações que deverão ser realizadas, resultados de ações, decisões que precisam ser tomadas, e cursos de qualificação. Não existe um tempo certo para esse processo de incubação. Existem casos de grupos que levam dois anos, outros que levam quatro, e assim por diante, pois cada grupo tem seu perfil. 
Esta incubadora não utiliza acompanhamento por indicadores para avaliar o processo de incubação, mas estão desenvolvendo para proporem no próximo edital que irão participar. Enxerga-se a importância de desenvolvimento de indicadores, para servirem de subsidio nos outros processos de incubação, analisando assim o que teve de certo e positivo nos empreendimentos. Servirá de monitoramento e avaliação constante do processo.

Segue abaixo o fluxograma com as fases descritas acima:

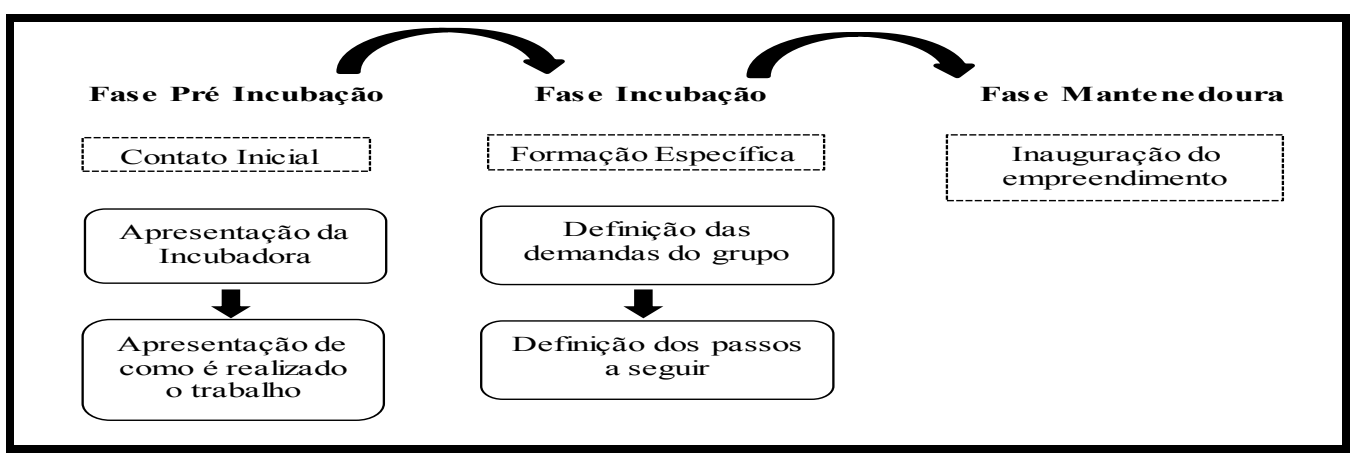

Figura 2 Fases de Incubação.

Fonte: Elaborado pelas autoras, com base na pesquisa.

\subsubsection{Incubadora $C$}

A incubadora $\mathrm{C}$ não possui uma forma metodológica de incubação padrão, pois a cada empreendimento são características específicas. Atualmente tem sido discutida essa carência e procurado contato com outras incubadoras para pensar em uma forma para utilizar.

O que é realizado de processo de incubação são duas ações iniciais: a ação 1 é quando o grupo procura a incubadora, e assim a equipe de incubação se organiza e estuda um trabalho a ser realizado. Pode ocorrer também da incubadora conhecer um grupo, saber da existência do mesmo, caracterizando assim a ação 2, que é onde ocorre essa aproximação e a equipe de incubação oferece o trabalho, a assessoria, na perspectiva de organizar o grupo para que ele possa caminhar com sucesso no empreendimento. Procura-se nesse processo estimular ao máximo o trabalho e construção coletiva, ou seja, faz-se o grupo pensar, refletir e decidir, sem que a equipe de incubação imponha a opinião, atuando assim na prestação de auxílio naquilo que os cabe.

Quanto aos encontros, são realizadas reuniões rotineiras duas vezes por mês e também uma assembleia por mês. Realizam-se também encontros semanais entre a equipe, onde discutem não só a relação de incubadora-incubados, mas também a relação equipeuniversidade. 
Umas das preocupações da incubadora são os indicadores, porque até então não se tem os mesmos construídos, de forma sólida e confiável, e isso é considerado pela equipe como uma falha, porém a construção de indicadores para acompanhamento é uma das metas da incubadora. Com isso, irão estabelecer uma reorganização, mas por enquanto está caminhando de forma devagar, pois a equipe encontra-se sem técnicos, e quanto aos alunos ocorre o caso de não poderem auxiliar integralmente, devido às provas, entre outras questões.

Tais ações seguidas no processo poderão ser visualizadas na figura abaixo:

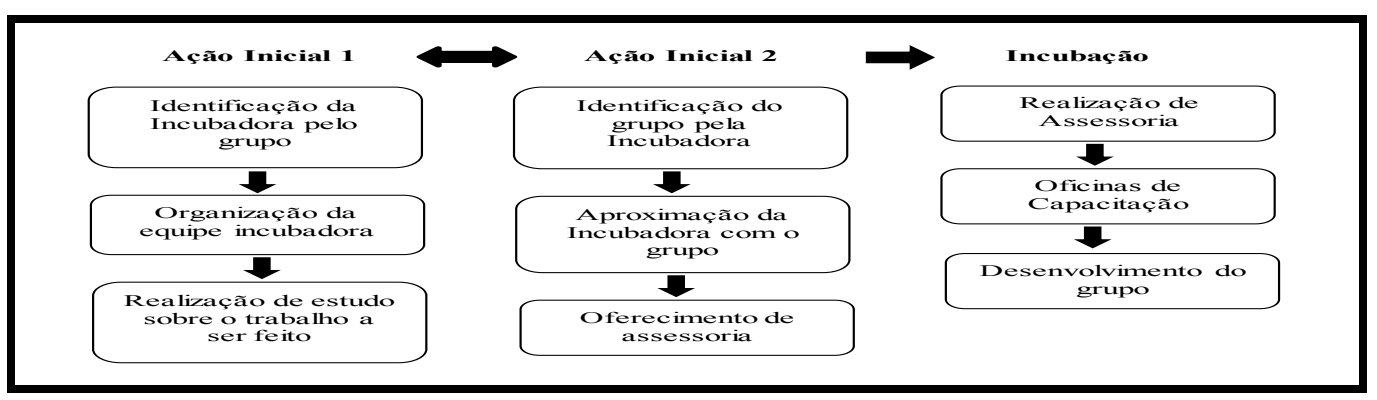

Figura 3 Fases de Incubação.

Fonte: Elaborado pelas autoras, com base na pesquisa.

\subsubsection{Incubadora D}

Quanto a Incubadora D, a mesma desenvolveu uma proposta de metodologia em que envolve um conjunto de atividades que ocorrerão na forma de oficinas, procurando desenvolver habilidades empreendedoras nos grupos, seguindo os princípios de economia solidária.

Os componentes do processo compreendem: ações formativas e direcionadas à estruturação do Empreendimento de Economia Solidária (EES) e atividades voltadas para a inserção do EES no mercado. O processo será norteado por metodologias participativas, dinâmicas de grupo e jogos estruturados. O processo segue representado pela figura abaixo: 


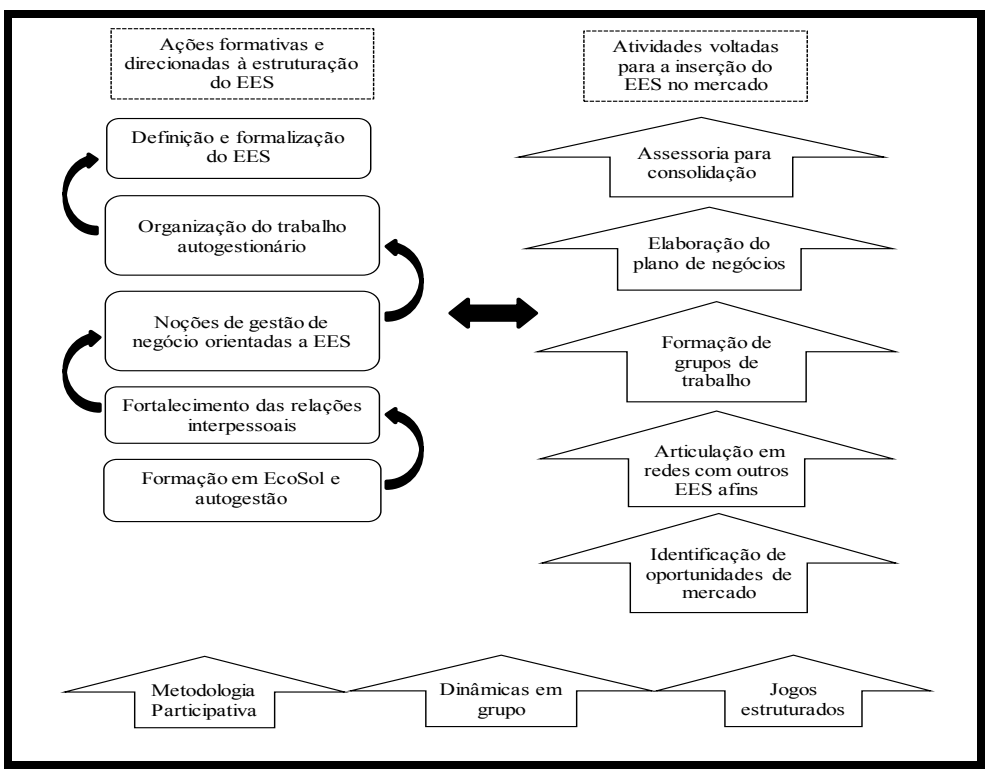

Figura 4 Metodologia de Incubação.

Fonte: Adaptado pelas autoras, com base na pesquisa.

Pretende-se assim trabalhar com os grupos os aspectos de formação em economia solidária, fortalecer as relações interpessoais entre os membros, identificar oportunidades de mercado e de articulação em rede, mostrar noções de gestão de negócios, assessoria para formulação do plano de negócio, orientação para definição da natureza do empreendimento, e assessoria para garantir que esses grupos se tornem autossustentáveis.

De início as oficinas irão ocorrer semanalmente, passando para quinzenalmente quando as atividades voltarem-se a um trabalho mais operacional, respeitando assim o ritmo de cada empreendimento. Paralelo a isso, os grupos serão estimulados e orientados a desenvolverem atividades no ambiente de negócios em que os mesmos irão atuar (ou atuam), conhecendo assim melhor o mercado.

Quanto ao projeto Restaurante-Escola Solidário, haverá a preparação dos alunos que irão atuar assessorando em processos específicos, para que procurem garantir a participação das beneficiárias nos processos decisórios. Assim, a incubação irá desempenhar um papel de fomentar a estruturação de novos empreendimentos, que serão constituídos por essas beneficiárias.

Para monitoramento e avaliação do processo de incubação, foi desenvolvida uma proposta de acompanhamento por indicadores, em os mesmos foram agrupados em quatro grupos, distribuídos em dois eixos: 1) qualitativos (viabilidade e estruturação cooperativa) e quantitativos (viabilidade e estruturação econômica); 2) incubação (fase de empreendimentos selecionados e incubados) e pós-incubação. 
Esta proposta acima de metodologia de incubação, que envolve os indicadores de acompanhamento, encontra-se na proposta submetida no edital para implantação da incubadora na universidade.

\subsubsection{Eixos de Acompanhamento}

Neste tópico será realizada análise das incubadoras quanto aos eixos de Legalização, Viabilidade Econômica e Capacitação.

Quanto ao eixo de Legalização, nos grupos trabalhados pelas incubadoras, verifica-se que muitos procuram organizar a documentação para poderem participar de editais do governo, mas ainda assim as equipes de incubação realizam um trabalho de conscientizar sobre a importância de legalizar, e os procedimentos para o mesmo.

No caso da incubadora A, foi relatado que realizam oficinas de legalização. Realiza-se esse trabalho, porém a incubadora não executa; ela mostra o caminho sobre o que deve ser feito e o que é necessário; auxilia a criar o estatuto, a como fazer as atas, para que deste modo o grupo vá realizar a ação externa, de tirar a documentação.

O relato da incubadora B é de que possui dois grupos legalizados, e um grupo que ainda não, o das beneficiárias do Bolsa Família, sendo um processo complexo para as mesmas devido à questão da vigilância sanitária e ambiental.

Quanto à incubadora $\mathrm{C}$, todos os grupos trabalhados são legalizados. Foi apresentado que o que os motivou a serem legais foi devido à força da lei.

Já a incubadora D, por estar iniciando seus trabalhos, ainda nenhum grupo tornou-se legalizado.

Quanto ao eixo de Viabilidade Econômico-Financeira, na incubadora A não foi detalhado como ocorre em cada empreendimento, há casos de alguns que já alcançaram um estágio de funcionamento de forma autogestionária, e outros que quanto à gestão tem bom funcionamento, mas a relação com o mercado ainda não está bem desenvolvida. Então cria-se um quadro bem heterogêneo. $\mathrm{Na}$ incubadora $\mathrm{B}$ vê-se que em todas as iniciativas as decisões são tomadas de formas autogestionárias. Como exemplo, tem-se a cooperativa que trabalha com uma fruta típica da região e que está em um estágio de amadurecimento em que ela mesma realizou uma festa na comunidade, promovendo o seu produto e mobilizando a cidade. É fruto de uma organização coletiva, dentro de uma perspectiva maior de solidariedade e cooperação. 
Já a incubadora $\mathrm{C}$, os empreendimentos incubados ainda não atuam de forma autogestionária. Eles tem certa dependência da universidade, ficando muito na expectativa do que irão fazer por eles, não tendo ainda uma cultura sólida de economia solidária. Mas a equipe enxerga que é um processo lento que precisa ser trabalhado, pois cada grupo tem seu tempo de amadurecimento. O que se tenta fazer é levar o grupo a pensar coletivamente, os quais estão tendo um progresso.

Quanto à incubadora $\mathrm{D}$, existe o caso do grupo de artesãs que desde quando a equipe de incubação fez o primeiro contato, as mesmas já possuíam uma organização própria, realizando a venda de seus produtos em uma feira no bairro. Esse mesmo grupo havia criado um regimento de como o grupo funcionaria.

No eixo de capacitação, as incubadoras mostraram realizar (a D ainda não iniciou, mas propõe realizar) capacitações através de oficinas, procurando trabalhar os princípios de economia solidária tanto com sua equipe quanto com as iniciativas, bem como oferecer assessorias para que os grupos se tornem autogestionários.

\section{CONSIDERAÇÕES FINAIS}

O presente trabalho teve como objetivo analisar as diferentes metodologias de incubação em incubadoras de empreendimentos de economia solidária, a partir do uso de indicadores para o acompanhamento das mesmas (quais sejam: legalização, viabilidade e capacitação).

Foram verificadas as características de cada incubadora da amostra, e percebeu-se que todas, independente de seus estágios de amadurecimento, passam por algumas dificuldades, as quais variam desde as questões de recursos, ferramentas metodológicas, parcerias, editais, participação discente, dificuldade de sensibilizar os grupos, entre outras.

Incubar iniciativas torna-se um trabalho muito complexo, pois envolve uma realidade de pessoas que passam por necessidade de sobrevivência e tem o desejo imediatista de se conseguir recursos, as quais muitas vezes não possuem o básico para poder funcionar, como um espaço para trabalharem, e esse cenário não é diferente de uma incubadora que está iniciando para aquela que já existe há muitos anos. Desenvolver nas pessoas e na comunidade em que as mesmas estão inseridas essa nova forma de se fazer economia, e fazê-las enxergar sob essa nova perspectiva são um desafio, mas que trará muitos benefícios. É um trabalho lento, mas que precisa ser desenvolvido, pois continuará a desenvolver um grande 
movimento, e com ele, futuramente, grandes redes de cooperativas e associações que atuam de forma coletiva, solidária, objetivando o bem-estar e a valorização do trabalho humano.

Então, vê-se que existem barreiras e desafios, mas também é importante olhar desde o início os benefícios, os pontos positivos de procurar desenvolver esses empreendimentos e os princípios de Economia Solidária. Atuar de forma que haja desenvolvimento dos eixos de legalização, viabilidade econômica e capacitação, pois com esses indicadores funcionando de acordo com os objetivos, os empreendimentos estarão dando bons resultados e atendendo às expectativas, se tornando autogestionários e maduros.

Deve-se assim procurar aprimorar as ferramentas e metodologias de incubação, para estarem atendendo de forma eficaz às novas demandas. E deste modo, aumentar a relação entre as incubadoras, para que as mesmas troquem experiências e façam emergir novas propostas de desenvolvimento.

Como limitação desta pesquisa, destaca-se o número e variedade de empreendimentos analisados. Sugere-se para pesquisas futuras: a) uma ampliação deste estudo sobre EES e maior diversidade geográfica dos mesmos e b) um aprofundamento dos estudos em ITCPs, especificamente nas questões ligadas à relação das cooperativas incubadas com suas parceiras, e como se dá a captação de recursos, fatores estes que acabam sendo uma barreira no processo de incubação.

\section{REFERÊNCIAS BIBLIOGRÁFICAS}

ABEGÃO, L. H.; ABREU, J. C. A. Criação da Incubadora Tecnológica de Empreendimentos de Economia Solidária do Médio Paraíba. Mimeo. Volta Redonda, 2013.

ARRUDA, M. Um novo humanismo para uma nova economia. In KRAYCHETE, G.; LARA, F.; COSTA, B. (Org.) "Economia dos setores populares: Entre a realidade e a utopia". Petrópolis: Editora Vozes, 2000.

BOCAYUVA, P. C. C. Incubadora Tecnológica de Cooperativas Populares/COPPE/UFRJ. In SPINK, P., \& CAMAROTTI, I.(Org.) "Redução da Pobreza e Dinâmicas Locais”. Editora FGV, 2001.

CANÇADO, A. C. Incubação de Cooperativas Populares: um estudo de multicaso na cidade brasileira de Camaçari/BA. Revista Venezolana de Economía Social, v. 25, 2013.

CANÇADO, A. C., \& GHIZONI, L. D. ITCP/NESol/UFT ontem, hoje e amanhã: um balanço dos primeiros cinco anos. Revista NAU Social, v. 4, 2013. 
CANÇADO, A. C.; CARVALHO, J. E. F. B.; PEREIRA, J. R. Gestão e Racionalidade: Análise da metodologia de incubação de cooperativas populares da ITCP/NESOL/UFT. REDES, Santa Cruz do Sul, v. 16, 2011.

CUNHA, G. C. Dimensões da luta política nas práticas de economia solidária In SOUZA, A. R.; CUNHA, G. C.; DAKUZAKU, R. Y. (Org.) "Uma outra economia é possível: Paul Singer e a economia solidária”. São Paulo: Editora Contexto, 2003.

CUNHA, A. M. S.; SILVA, A. C.; BORGES, D. P. Incubação de um empreendimento de economia solidária: o trabalho na ASCAMPA-Associação de Catadores(as) de Matérias Recicláveis da região centro norte de Palmas-TO. In CANÇADO, A., \& GHIZONI, L.(Org.) "Desenvolvimento, Gestão e Questão Social: Uma abordagem interdisciplinar". Palmas: Editora Didática, 2011.

CORAGGIO, J. L. Una alternativa socioeconómica necesaria: La economía social. Universidad Nacional de General Sarmiento, 2003.

CRUZ, A. É caminhando que se faz o caminho - diferentes metodologias das incubadoras tecnológicas de cooperativas populares no Brasil. Revista Venezolana de Economía Social, v.8, 2000.

CRUZ, L. F. Estudo de indicadores para empreendimentos cooperativos. II ENEDS, Rio de Janeiro, 2005.

FRANÇA FILHO, G. C. A temática da economia solidária e suas implicações originais para o campo dos estudos organizacionais. Revista de Administração Pública, v.37, 2003.

GAIGER, L. I. A outra racionalidade da economia solidária. Conclusões do primeiro Mapeamento Nacional no Brasil. Revista Crítica de Ciências Sociais, v.79, 2007.

Katál, v.11, 2008.

. A economia solidária e o valor das relações sociais vinculantes. Revista

GATTAI, S., \& BERNARDES, M. A. Papel e responsabilidades da universidade no processo socioeducativo presente em movimentos de economia solidária. Revista de Administração Mackenzie, v.14, 2013.

GIL, A. C. Métodos e Técnicas de Pesquisa Social. São Paulo: Editora Atlas, 2008.

LAVILLE, J. L. A economia solidária: um movimento internacional. Revista Crítica de Ciências Sociais, v. 84, 2009.

PAES DE PAULA, A. P., \& CALBINO, D. Economia Solidária: Uma investigação sobre o estado da arte. Gestão Contemporânea, 2013.

SEN, A. Desenvolvimento como Liberdade. São Paulo: Companhia das Letras, 2000.

SINGER, P. Entrevista com Paul Singer. São Paulo: Entrevista concedida a Revista Gerenciais, 2003. 
. Economia Solidária: entrevista com Paul Singer. Entrevista concedida a Estudos Avançados v.22, 2008.

SOUZA, A. R. Economia solidária: um movimento nascente da crise do trabalho In SOUZA, A. R.; CUNHA, G. C., DAKUZAKU, R. Y. (Org.) "Uma outra economia é possível: Paul Singer e a economia solidária”. São Paulo: Editora Contexto, 2003.

ITCP. Incubadora Tecnológica de Cooperativas Populares. Os tempos do Processo de Incubação. Rio de Janeiro, 2014. Disponível em:

http://www.itcp.coppe.ufrj.br/metod tempos.php. Acesso em: 27 de maio 2014.

WAUTIEZ, F.; SOARES, C. L. B.; LISBOA, A. M. Indicadores de La Economía

Solidaria. (pp.177-182). In: A outra economia. CATANI, A. D. (Org.). Porto Alegre: Veraz Editores, 2003. 